GHANA JOURNAL OF DEPARTMENT OF HEALTH, PHYSICAL EDUCATION AND RECREATION, SPORTS AND DANCE (GJOHPERSD)

\author{
Volume 9, Year 2016
}

A JOURNAL OF THE DEPARTMENT OF HEALTH, PHYSICAL EDUCATION AND RECREATION (HPER)

UNIVERSITY OF CAPE COAST

GHANA, WEST AFRICA 
Sports and Dance (GJOHPERSD)

\title{
Body Composition of Kwara State Basketball Players - Implications for Peak Performance
}

\author{
${ }^{* 1}$ Dominic Olufunmilola. L, ${ }^{1}$ Talabi Adetayo. E, \\ ${ }^{2}$ Kayode, Bode, ${ }^{3}$ Ongbinde
}

Ayodele.T, ${ }^{3}$ Ojoawo Adesola. $O$ \& ${ }^{1}$ Onifade, O. A.

${ }^{1}$ Department of Human Kinetics and Health Education, Faculty of

Education, University of Ilorin, Nigeria.

${ }^{2}$ Department of Epidemiology and Community Health,

University of Ilorin, Ilorin, Nigeria

${ }^{3}$ Medical Rehabilitation Department, College of Health Sciences, Obafemi Awolowo

University Ile-Ife Osun State, Nigeria.

*Corresponding author - E-mail- lolafunmidom@gmail.com.

$$
\text { Tel.:+234(0)803-658-4850. }
$$

\begin{abstract}
This study was carried out to evaluate the body composition of Basketball players in Kwara State, Nigeria. Physical characteristics of age, height and weight, the percentage body fat, fat mass, fat free mass and muscle mass were measured using standardized methods. Purposive sampling technique was used to select the participants made up of twelve (12) junior and fifteen (15) senior male basketball players. Portable Bathroom-type Hanson, scale (model B1801) was used to measure weight in kilogrammes, Holtain Stadiometre for height in centimetres and Slim-guide Skinfold callipers (model MI 48170, U.S.A). One-way ANOVA was used to analyse the difference in physical characteristics of the participants; t-test was used to determine difference in the body composition of the senior and junior basketball players. Significant difference was found in the body composition. The senior team had significantly higher fat free muscle mass and less fat and percentage body fat (4.69) that was too low for continuous vigorous intensity workout. However, there were no significant
\end{abstract}


Olufunmilola et al differences in the fat mass and fat free mass; while significant difference was found in percent body fat, BMI and muscle mass of both the senior and junior teams. This implies that the senior team has better musculature than the junior team. It was concluded that there is need for nutritional intervention and carbohydrate loading prior to performance to meet up the energy demand for daily training programme and during performance in order to improve performance ability of the senior basketball players.

Key words-, Body fat, Muscle mass, Lean body mass, Nutrition, Performance. 


\section{Introduction}

Basketball is one of the most popular sports in the world and is a game played by both males and females across many age groups and levels of participation, from recreational to professional sports in Nigeria. Sports performance is typically determined by the ability to execute skills and assignments at a planned effort level (Plisk, 2011). The ability to shoot in the sport of basketball is a 'key skill' in the game; therefore an ability to shoot successfully from variety of distances would naturally be desirable and must be pursued in order to excel close this gap (Walters, Hudson and Bird, 1990). Players' ability to control the trajectory of the ball is directly dependent upon their ability to control the acceleration forces generated by their own body, indicating that the size, body shape or proportions of a player will impose constraints upon his/her capacity for sport performance (Oladunni \& Sanusi, 2013; Folasire, Akomolafe, \& Sanusi, 2015; Abdullahi et al, 2017). Most elite basketball players have tall muscular, well balanced physiques (Smith \& Thomas, 1991; Asha, Kasturiba, Naik, \& Malagi, 2009), but have varying anthropometric variables depending on the player's playing position (Chan, 2004). Understanding the components of the body physique is important for better monitoring of training and dietary programmes (Gerodimus, Manou, Kellis \& Kellis, 2005). Williams et al (1992) explained that excess weight associated with fatness tends to have negative influence on aerobic capacity and on test batteries in which the body must be lifted or moved rapidly. This indicates that basketball players must not carry unnecessary fat to avoid hindrances in their movement and performance. Commenting on body fat, Folasire, et al (2015) noted that higher percent body fat was found to be significantly related with poor performance in endurance, speed and agility sporting events, of which Basketball is one. In addition, there is a close relationship between nutritional practices and athletic performance (Salarkia, Kimiagar \& Aminpour, 2004), regarding fuel supply for physical activity and body composition where the proportion of fat to muscle mass is considered. 
The body is typically made up of fat free mass (FFM) and available amount of fat (fat mass). Body composition includes muscles, bones, and nerve fibres coverings, as well as essential fats which the body must possess for cell wall construction, and other structures stressing the importance of balanced diet. Pradhan and Behera (2013) regarded FFM as lean body mass (LBM) and defined it as the total body weight minus the weight of the stored fat. Gutin (1980) explained that LBM is relatively constant and that body composition changes due mainly to fat deposition. Amusa, Igbanugo and Toriola, (1998) emphasized that lean body weight is a qualitative measure of LBM expressed in kilograms $(\mathrm{kg})$ or pounds (lb). Therefore for effective participation in sports, the desirable body composition needs to be sought (Toriola, 1999). The more the lean body mass, the better. The size of muscle accounts for increased strength and performance in power activities such as jumping to rebound, or shooting in basketball, or the running up and down for the 40 minutes stopping time game. Therefore, the right body composition is very crucial to excellence in basketball. Body composition testing is not just about measuring fat it is a very effective tool for planning, monitoring progress, and improving current athletic status, part of a rehabilitation protocol, offering encouragement, and finding irregularities in behaviour (Weatherwax-Fall, 2012).

Many studies have only focused on the nutritional deficiencies and health of athletes (Mathew, 2003; Oladunni \& Sanusi, 2013; Trakman, Forsyth, Devlin \& Belski, 2016; Penggalih, Juffire, Sudargo \& Sofro, 2017). Recently, research identified low energy availability as the hazard in sports that require weight reduction, and quantified its dose-dependent effects on metabolic and reproductive function (Academy of Nutrition and Dietetics [AND], Dietitians of Canada [DC] \& American College of Sports Medicine [ACSM], 2016). This is more significant during training and competition in sports of high intensity and long duration. During times of high-intensity training like basketball, adequate energy needs to be consumed to maintain body weight, maximize the training effects, and maintain health. Body weight influences 
an athlete's speed, endurance, and power, while composition affects an athlete's strength, agility, and appearance. Most athletes require a high strength-to-weight ratio to achieve optimal athletic performance, and because body fat adds to weight without adding to strength, low body fat percentages are often emphasized within many sports (Position of the American Dietetic Association and the Canadian Dietetic Association, 1993). On the other hand, too little body fat results in deterioration of health and performance especially in sports like basketball where strength and agility is emphasized.

The Kwara State basketball teams have been observed to consistently lead in most of their matches during the first three quarters but perform poorly in few minutes towards the end of the last quarter, which have led to their losing out in crucial competitions. In some competitions, for example, Milo Nestle Nigeria Secondary Schools Sports, National Sports Festival, both teams have been observed to struggle with weak passes, poor shooting percentage towards the end of their games. Having a certain the ratio of muscle to fat mass, is related to athletic performance, a correct proportion increases strength, power and agility (Spaniol, 2002). Furthermore, gaining lean muscle is not just about the exercise protocol but depends on nutritional intake and timing (Biolo, Williams, Fleming \& Wolfe, 1999; Rasmussen, Tipton, Miller, Wolf, \& Wolfe, 2000; Weatherwax-Fall, 2012). Therefore, we assumed that rapid depletion of energy supply to the working muscle or exhaustion was responsible for poor performance of the Kwara State basketball teams during the fourth quarter of matches. Most studies have attributed poor performance to physical abilities such as physical fitness and conditioning, which may not apply to all situations especially during competition. Furthermore, it has been found that three out of four student athletes may be having poor nutrition and thus affecting the performance of the entire team. However, several studies regarding athletes and nutrition (Laughlin \& Yen, 1996, 1997; Williams \& Rollo, 2015), did not compare junior and senior basketball players' body composition to find out if nutrition could be a factor for 
having good performance at the beginning of a match and ending it poorly. Based on the study of Dominic (2006), the senior basketball players were found to have better musculature but little \%body fat (4.67\%) and led to this follow-up study to compare the junior players with the senior players if the same result would be found. Therefore, the purpose of this study was to evaluate the differences in fat mass and fat-free mass; percent body fat and body mass index (BMI); and the muscle mass between junior and senior Kwara State basketball players and suggest ways that will enable them maintain consistent ability to sustain optimal performance throughout a match.

\section{Materials and Methods}

Participants - The participants for the study were twelve players from the junior team and fifteen players from the senior team of the Kwara State, Nigeria male basketball players who volunteered, gave informed consent and completed the measurements. The junior players have represented Kwara State in Nigeria Secondary School Sports competitions and Under 21 championships. The senior team have represented the state at the National Sports Festival, National division 1 League and Nigerian University Games (NUGA). The age of the junior players ranged between 15 and 21 years, while that of the senior players was 21 and 39 years.

Procedure - The physical characteristics of the players were taken and they included age given by the players (taken to the nearest 0.1 year), a portable Bathroom-type Hanson scale, model B1801 was used to measure weight in kilogrammes. A Holtain Stadiometre was used to measure height in centimetres. The Slim-guide Skinfold callipers (model MI 48170, U.S.A) was used to measure 8 sites skin folds to determine the percentage body fat $(\% \mathrm{BF})$, fat mass and muscle mass. The measurements were taken in the indoor Sport Hall of the Kwara State Sports Complex before evening training with the help of research assistants. The technique and the equation of Durnin and Womersley (1974) was used to 
calculate body density while \%sBF was calculated using the Brozek. et al. (1963) formula:

Fat mass $(\mathrm{Kg})=$ body mass $\mathrm{x} \% \mathrm{BF}($ expressed in decimal);

$\mathrm{BMI}=$. Weight $\square$ height $^{2}$;

Fat Free Mass; (Lean body weight $)=($ Body mass in $\mathrm{kg})-($ fat mass in $\mathrm{kg}$ ).

This technique has a reliability coefficient of 0.8 . In addition, muscle mass was determined based on the equation of Martin and Drinkwater (1991):

Muscle mass $(\mathrm{g})=\mathrm{s}(0.0553 \mathrm{CGT}(\mathrm{sq})+0.0987 \mathrm{FG}(\mathrm{sq})+0.0331$ CGC (sq) -2444.

Where: $\mathrm{S}=$ stature; $\mathrm{CTG}=$ corrected mid-thigh girth; $\mathrm{FG}=$ forearm girth and $\mathrm{CCG}=$ corrected calf girth.

$\mathrm{CTG}=\frac{\mathrm{TG}-\text { mid }- \text { thigh skin fold }}{10}$

$\mathrm{CCG}=\frac{\mathrm{CG}-\text { calf skinfold }}{10}$

Three measurements were taken for all the variables and the mean was recorded (ISAK, 1999).

Analysis of Data- For the analysis of the physical characteristics of the participants (Table 1), Mean and Standard deviation were used to describe the data while One-way ANOVA was used to determine the differences between the guards, forwards and centres in both junior and senior teams. For the correlation of body composition variables, (Table 2), student's t-test was used to test significant difference between fat mass, fat free mass, lean body mass, \%BF and BMI of the junior and senior basketball teams at an alpha level of 0.05 significance. The SPSS application package version 20.0 was used for statistical analysis. 


\section{Results}

Olufunmilola et al

Table 1: Physical Characteristics of the Kwara State Male Basketball Teams

\begin{tabular}{|c|c|c|c|c|c|c|c|c|}
\hline Variable & Group & $\mathbf{N}$ & Mean & S.D. & Guard & Forward & Centre & $\mathbf{F}$ \\
\hline \multirow{2}{*}{$\begin{array}{l}\text { Age } \\
\text { (yrs) }\end{array}$} & Junior & 12 & 17.92 & 1.56 & - & - & - & - \\
\hline & Senior & 15 & 24.27 & 3.2 & - & - & - & - \\
\hline \multirow{2}{*}{$\begin{array}{l}\text { Height } \\
(\mathrm{cm})\end{array}$} & Junior & 12 & 176.17 & 9.04 & $160.33(3)$ & $177(7)$ & 194.0(2) & $12.34^{*}$ \\
\hline & Senior & 15 & 183.2 & 9.04 & $176.21(7)$ & $189.5(5)$ & 189.9(5) & $7.66^{*}$ \\
\hline \multirow{2}{*}{$\begin{array}{l}\text { Weight } \\
(\mathrm{kg})\end{array}$} & Junior & 12 & 67.92 & 13.22 & $55.33(3)$ & 69.86(7) & $80.0(2)$ & 3.16 \\
\hline & Senior & 15 & 79.89 & 9.37 & $73.27(7)$ & $83.8(5)$ & $88.69(5)$ & $5.98^{*}$ \\
\hline
\end{tabular}

*sig.: 0.05

One-way ANOVA of the participants' physical characteristics of was presented in table 1. Expectedly there was significant variability between the senior players who were older $(24.27 \pm 3.2$ years vs. $17.92 \pm 1.56$ years $)$, taller $(183.2 \pm 9.04 \mathrm{~cm}$ vs. $176.17 \pm$ $9.04 \mathrm{~cm})$ and heavier $(79.89 \pm 9.37 \mathrm{~kg}$ vs. $67.92 \pm 13.22 \mathrm{~kg})$ than the junior players $(F=12.34)$. There was significant difference among the players in the junior team $(F=7.66)$, the guards were the shortest $(160.33 \pm 3.0 \mathrm{~cm})$, they were smaller than the forwards $(177.7 \pm 7.0 \mathrm{~cm})$, while the centre players were the tallest $(194.0 \pm$ $2.0 \mathrm{~cm}$ ) and heaviest (guards $=53.33 \pm 3.0 \mathrm{~kg}$; forwards $=69.86 \pm$ $7.0 \mathrm{~kg}$; centres $=80.0 \pm 2.0 \mathrm{~kg}$ ). There was also significant difference in the senior team $(\mathrm{F}=5.98)$, the guards were the smallest and shortest (guards $=176.21 \mathrm{~cm}$ ) of all, while there was no significant difference between the forwards and centre $(189.5 \pm$ $5.0 \mathrm{~cm}$ vs. $189.5 \pm 5.0 \mathrm{~cm} ; \mathrm{F}=3.16)$ players considering the height and weight (guards $=73.27$; forwards $=83.8 \pm 5.0 \mathrm{~kg}$; centres $=$ $88.69 \pm 5.0 \mathrm{~kg})$. 
Table 2: Independent Sample t-test Analysis for Body Composition of Kwara State Senior and Junior Teams

\begin{tabular}{|c|c|c|c|c|c|c|}
\hline & $\begin{array}{l}\text { VARIAB } \\
\text { LE }\end{array}$ & $\begin{array}{l}\text { TEA } \\
\text { M } \\
\end{array}$ & $\mathbf{N}$ & $\begin{array}{l}\text { Mean } \pm \\
\text { S.D }\end{array}$ & MD & ' $t$ ' \\
\hline \multirow[t]{4}{*}{1} & Fat Mass & Junio & 1 & $44.4 \pm 16.6$ & & \\
\hline & $(\mathrm{Kg})$ & $\mathrm{r}$ & 2 & 2 & $7.30 \pm 1.3$ & \\
\hline & & Senio & 1 & $37.10 \pm 17$ & & 1.30 \\
\hline & & $\mathrm{r}$ & 5 & 51 & & \\
\hline \multirow[t]{4}{*}{2} & Fat Free & Junio & 1 & $43.73 \pm 11$ & & \\
\hline & Mass (Kg) & $\mathrm{r}$ & 2 & & $29.86 \pm 5$ & \\
\hline & & Senio & 1 & $73.59 \pm 17$ & & 1.29 \\
\hline & & $\mathrm{r}$ & 5 & 30 & & \\
\hline \multirow[t]{4}{*}{3} & Muscle & Junio & 1 & $33.19 \pm 13$. & & \\
\hline & Mass (kg) & $\mathrm{r}$ & 2 & 59 & $15.37 \pm 5$ & - \\
\hline & & Senio & 1 & 48.56 & 37 & 3.54 \\
\hline & & r & 5 & \pm 7.86 & & * \\
\hline \multirow[t]{4}{*}{4} & \%Body & Junio & 1 & $6.70 \pm 2.03$ & & \\
\hline & Fat & r & 2 & $4.69 \pm 2.21$ & $2.01 \pm 0.1$ & 2.44 \\
\hline & & Senio & 1 & & 8 & $*$ \\
\hline & & $\mathrm{r}$ & 5 & & & \\
\hline \multirow[t]{4}{*}{5} & BMI & Junio & 1 & $21.78 \pm 2.5$ & & \\
\hline & & r & 2 & 3 & $2.01 \pm 0.4$ & - \\
\hline & & Senio & 1 & $23.79 \pm 2.1$ & 1 & 2.21 \\
\hline & & $\mathrm{r}$ & 5 & 2 & & $*$ \\
\hline
\end{tabular}

*Sig. 0.05

Table 2 show independent sample t-test comparison of body composition of senior and junior basketball teams of Kwara State. 
There was no significant difference found between the junior and senior male Kwara State players in fat mass $(44.4 \pm 16.62 \mathrm{~kg}$ vs. $37.10 \pm 17.51 ; \mathrm{MD}=7.30 \pm 1.31 ; \mathrm{t}=1.30 ; \mathrm{p}>0.05)$ and fat free mass $(43.73 \pm 11.62 \mathrm{~kg}$ vs. $73.59 \pm 17.30 \mathrm{~kg} ; \mathrm{MD}=29.86 \pm 5.68$ $\mathrm{kg} ; \mathrm{t}=1.29 ; \mathrm{p}>0.05)$. The junior team had significantly higher $\% \mathrm{BF}(6.70 \pm 2.03 \%$ vs. $4.69 \pm 2.21 \% ; \mathrm{MD}=2.01 \pm 0.18 \%, \mathrm{t}=-$ $3.54, \mathrm{p}<0.05)$ and lower BMI $\left(21.78 \pm 2.53 \mathrm{~kg} / \mathrm{m}^{2}\right.$ vs. $23.79 \pm$ $\left.2.12 \mathrm{~kg} / \mathrm{m}^{2} ; \mathrm{MD}=2.01 \pm 0.41 \mathrm{~kg} / \mathrm{m}^{2} ; \mathrm{t}=-2.21 ; \mathrm{p}<0.05\right)$ than the senior team. The junior team had significantly lower muscle mass $(33.19 \pm 13.59 \mathrm{~kg}$ vs. $48.56 \pm 7.86 \mathrm{~kg} ; \mathrm{MD}=15.37 \pm 5.37 ; \mathrm{t}=3.54 ; \mathrm{p}$ $<0.05$ than the senior team.

\section{Discussion}

Height appears to be a critical component of potential performance which is most relevant for the centre and forward positions. These differences may be explained by the fact that adequate weight is necessary for stability with balance in motion, starting and stopping in addition to speed of arms and hands (Oranugo, 1997). The increase in body size results in stronger players (Montegory, 2006). The guard position generally requires greater emphasis on ball handling skills including passing and shooting specifically (Miller \& Bartlett, 1996; Chan, 2004). Furthermore, in comparison of the Kwara State teams to national and international players studied (Carter, 1970; Carter, et. al 1982; Pollock et al, 1982; and Oranugo, 1997; and Chan, 2004) the senior players were not inferior in height and weight, especially the forwards and centres to the average height range of $186.9-189.4 \mathrm{~cm}$ and weight range of $76.7-90.9 \mathrm{~kg}$ of the studied players, which is comparable with the world standard.

In the body composition, the junior players carry more fat mass $(44.67 \mathrm{~kg})$ and less free fat mass $(43.78 \mathrm{~kg})$ than the senior basketball players, indicating a better lean body weight by the senior players. Hoeger's (1989) study explained that the alterations in body composition most often attributed to aerobic exercise are a decrease in fat weight and maintenance or slight increase in fat free 
mass due to the burning of calories and loosing of body fat. This is an indication of the significance of athletes' weight monitoring and nutrition. Metabolic rate is also directly proportional to leans body mass.

Considering percent body fat and BMI, the junior players had significantly high \% BF and lower BMI than that of the senior players. However, both are too low compared to the study of (Durnin \& Womersley, 1974) who reported that elite basketball male players had 13.1\%BF while Wilmore (1983) reported $8.9 \%$ in his own study. Furthermore, as reported by Oranugo (1997), study of professional basketball players showed a mean \% BF of 9.6\% and of University basketball players by Oranugo (1984) to be 9.8\%. This connotes that though the senior and junior Kwara State players are carrying less fats adequate for health and wellness as indicated in the normative table (Fahey, Insel, \& Roth, 2001); it was too little for their weight, height as basketball players and too low for optimal performance.

Though Chan (2004) reported that basketball as a sport requires speed and explosive power, excess fat is undesirable as it will be detrimental to performance, so also the development in size, strength, and speed has both positive and negative consequences (Montgomery, 2006) especially with less than required fat mass. However, there is still a need to possess a threshold of fat needed to generate energy (Chan, 2004). Fahey, Insel and Roth (2001) added that though low \%BF is not a prevalent problem, having too little $\% \mathrm{BF}$ is also dangerous $(5 \%$ in men; $8 \%$ in women) and that too much or too little can have negative effects on health, performance and even self-image. This puts the senior team in the danger zone, especially with participation in vigorous and demanding sports like basketball. The risk for diseases and disorders caused by too little body fats are associated with malnutrition Heyward 1998; Oladunni \& Sanusi, 2013. The senior team with less than $5 \% \mathrm{BF}$ fat is in this risk zone and, therefore, need nutritional intervention. Fahey et al. (2001) highlighted that both moderate to intensive exercises and 
endurance training on frequent bases burn significant number of calories and increases resting metabolic rate (RMR); and that for athletes, $40 \%$ of energy comes from fuel derived from fat during recovery. Combinations of low levels of eating, high physical performance and disordered eating habits are associated also with stress fractures and other injuries. Team sports athletes need to follow sound nutrition principles to optimize their body composition, recover daily after training (Asha, Kasturiba, Naik, \& Malagi, 2009)._Therefore, senior Kwara State basketball players needs to develop good nutritional habits.

The superiority of the senior basketball players of Kwara State demonstrated by high muscle mass (48.562.kg) as against that of the junior players $(33.194 \mathrm{~kg})$ provides a better advantage to be stronger. Lean body mass is considered to be one of the best predictors of athletes' success (O'shea, 2000). However, according to Fahey, Insel and Roth (1994), the more muscle mass the higher metabolic rate, thus indicating that the senior players require more calories than junior team to meet up with their energy needs. Furthermore, following a hard workout, if the muscle glycogen is not replaced adequately through nutrition intervention, there might not be enough fuel to sustain the intensity of subsequent workouts.

Rosato (1994) reported that muscles expended calories much more than fat and that those who involve in intense exercise increase their fat-free mass, associated with higher metabolic rate, due to burning of calorie, thus raising the total energy expenditure, which increases the need for caloric intake. This study supports the assertion of O'Shea (2000) that athletes can develop lean muscle mass and strength without assuming the medical risks involved through the correct balance of nutrition, rest and exercise, to achieve maximum peak athletic performance. Similarly, Montgomery (2006) found that nutrition is a factor contributing to larger players and that during games and workouts players are discovered to consume specialized beverages and products that facilitate their recovery. In addition, Juhn (2004), reported that in recent years, some players have used supplements like creatine that 
result in a small weight gain, but it is an individual's choice and requires caution and monitoring by sport nutrition experts in order to prevent its adverse effects of kidney damage, muscle strain and tears (Mayhew, Mayhew, Ware, 2002); Kreider, Melton, Rasmussen et al, 2003; Groeneveld et al., 2005).

The result of the collaborative study carried out by the American Dietetic Association (ADA), Dietitians of Canada (DC), and the American College of Sports Medicine (ACSM) (2009) deduced that physical activity, athletic performance, and recovery from exercise are enhanced by optimal nutrition. They therefore, recommended appropriate selection of foods and fluids, timing of intake, and supplement choices for optimal health and exercise performance. As such, sports beverages containing carbohydrates and electrolytes may be consumed before, during, and after exercise to help maintain blood glucose concentration, provide fuel for muscles, and decrease risk of dehydration and hyponatremia (ADA, ACSM \& DC, 2008). The senior players can take advantage of these findings for maximal performance, since nerves and muscles cannot function without steady supply of glycogen.

Athletes like the basketball players, need to consume adequate energy during periods of high-intensity and/or longduration training to maintain body weight and health and maximize training effects. Low energy intakes can result in loss of muscle mass; loss of or failure to gain bone density; an increased risk of fatigue, injury, and illness; and a prolonged recovery process (ADA, ACSM \& DC, 2009). More so, athletes often desire to change their body composition to help them succeed in sport. Some sports promote leanness as part of the success factor, which in turn likely promotes dieting behaviours (Watson \& Buell, 2009). Nevertheless, basketball players require adequate nutrients to sustain their performance during workout and match.

\section{Conclusion}

The senior players are significantly different from the junior basketball players in terms of weight, height, and higher 
muscle mass, lower \%BF though below the threshold. This calls for serious attention of the players and coaches if optimal performance is expected in future outings. Also in the $\% \mathrm{BF}$, there is a need for nutritional intervention due to too little body fat, in order to meet up with their body energy needs, as a result of greater fat free mass and muscle mass. This demands from the body, more calories and restoration of glycogen depleted as a result of extensive daily hard workout in basketball training sessions. The low body fat has been established to have negative effect on health, and performance. A balance between meeting the body glycogen demands for fuel and consistent training and harmonized or synchronized performance of the senior players is imperative.

\section{Recommendations}

Therefore it is recommended that the team coaches need to monitor the body composition of the basketball players to prevent loss of body muscle mass and fat weight to the detriment of health and performance of the players especially the senior team. Special carbohydrate loading could be administered to the players prior to the competition. This might enhance enough glycogen reserve that will be sufficient for energy supply throughout the four quarters of basketball match. 


\section{References}

Abdullahi, Y., Toriola, A. L., Goon, D. T., Paul, Y., Igbokwe, U. \& Suarau, M. A. (2017). Anthropometric and motor performance characteristics of Nigerian badminton players. Asian Journal of Scientific Research 10(3), 244 - 251.

Academy of Nutrition and Dietetics (AND), Dietitians of Canada (DC), and American College of Sports Medicine (ACSM). (2016). Nutrition and athletic performance - Joint Position Statement. http://dx.org10.1249/MSS.0000000000000852.

Amusa, L.O., Igbanugo, V.C. \& Toriola A.L. (1998). Experiments and laboratory experiences in exercise physiology. ( $\left.2^{\text {nd }} \mathrm{ed}.\right)$ Nigeria: LAP Publication.

Asha, L., Kasturiba, B., Naik, R. K., \& Malagi, U. (2009). Nutritional status of basket-ball players of Dharwad city. Karnataka Journal of Agriculture. Science, 22(1), 161-165.

Biolo, G., Williams, B. D, Fleming, R. Y, \& Wolfe, R. R. (1999). Insulin action on muscle protein kinetics and amino acid transport during recovery after resistance exercise. Diabetes, 48,949 - 957.

Brozek, J., Grande, F., Anderson J. T., \& Keys, A. (1963). Desitometric analysis of body Composition: reversion of some qualitative assumption. Annuls New York Academy of Science, $\quad 110, \quad 113-140 . \quad$ DOI: $10.1111 / \mathrm{j} .1749-$ 6632.1963.tb17079.x

Carter, J.E.L. (1970). Somatotype of athletes-review. Human Biology, 42, 535.

Carter, J. E., Ross, W., Aubry, P., Hebbe Link M. \& Borms, J. (1982) Anthology of Montreal Olympic athlete, Medicine and Sport 16: 25-51.

Chan, D. (2004). Fitness Testing Assignment-Basketball. Exercise Physiology Educational Resources; Curtin University of Technology. Retrieved on 27/1/2006@ file://E:Fitness Testing Assignment-Basketball.html.

De Souza, M. J., Van Heest, J., Demers, L. M.. \& Lasley, B. L. (2003). Luteal phase deficiency in recreational runners: Evidence for a hypometabolic state. Journal of Clinical Endocrinology and Metabolism, 88, 337-346. 
Dietitians of Canada (DC), the American College of Sports Medicine (ACSM) \& the American Dietetic Association, (ADA). (2009). Nutrition and Athletic Performance. Special Communications: Position Stand. Journal of Medicine \& Science in Sports \& Exercise, 41(3), 709-731.

Dominic, O. L. (2006). Evaluation of the body proportions of Kwara State basketball players. Journal of Physical Education and Research, 11, 1580-1587.

Durnin, J. V. G. A., \& Womersley, J. (1974). Body fat assessment from the thickness measurements on 481 men and women aged from 16-72 years. British Journal of Nutrition 32, 7797.

Fahey, R. D, Insel, P. M., \& Roth, W. T. (1994). Fit \& Well: Core concepts and lab in Physical Fitness and Wellness. Mountain View, C.A: Mayfield Publishing Company.

Fahey, R. D., Insel, P. M., \& Roth, W. T. (2001). Fit \& well: Core concepts and lab in Physical Fitness and Wellness. Mountain View, C.A: Mayfield Publishing Company.

Folasire, O. F., Akomolafe, A. A. \& Sanusi, R. A. (2015). Does nutrition knowledge and practice of athletes translate to enhanced athletic performance? cross-sectional study amongst Nigerian undergraduate athletes. Global Journal of Health Science 7(5), 215 - 225.

Gerodimus, V., Manou, V. Kellis, E. \& Kellis, S. (2005). Body composition characteristics of elite male basketball male playres. Journal of Human Movement Studies 49(13), 2130.

Groeneveld, G. J., Beijer, C., Veldink, J. H., Kalmijn, S., Wokke, J. H., \& Van den Berg, L. H. (2005). Few adverse effects of long-term creatine supplementation in a placebo-controlled trial. International Journal Sports Medicine, 26, 307-13.

Gutin, B. A. (1980) Model of physical fitness and dynamic health. Journal of Physical Education Recreation, 14, 49-55.

Heyward, V. H. (1998). Advance fitness assessment and exercise prescription. Champaign Illinois: Human Kinetics. 
Hoeger, W. W. K. (1989). Lifetime physical fitness and wellness. Englewood: Morton Publishing.

International Society for the Advancement of Kin anthropometry (ISAK) (2003). International Standards for Anthropometric Assessment. Not complete

Juhn, M. S. (2004). Creatine supplementation in ice hockey: a review of applicability and safety. In Safety in ice hockey. Vol. 4. Edited by D. J. Pearsall and A. B. Ashare. American Society for Testing and Materials International, West Conshohocken, Penn. pp. 224-236.

Kreider, R. B., Melton, C., Rasmussen, C. J., Greenwood, M., Lancaster, S., Cantler, E. C., Milnor, P., \& Almada A. L. (2003). Long-term creatine supplementation does not significantly affect clinical markers of health in athletes. Molecular Cell Biochemistry, 244, 95-104.

Laughlin, G. A., \& Yen, S. S. C. (1996). Nutritional and endocrine-metabolic aberrations in amenorrheic athletes. Journal of Clinical Endocrinology and Metabolism, 81, 4301-4309.

Louck, A. B. (2003). Energy balance and body composition in sports and exercise. Journal of Sports Sciences, 22, 1-14.

Martin, A. D., \& Drinkwater, D. T. (1991). Variability in the measure of Body fat. Sports Medicine, 11(3), 277-288.

Mayhew, D. L., Mayhew, J. L., \& Ware, J. S. (2002). Effects of long-term creatine supplementation on liver and kidney functions in American college football players. International Journal of Sport Nutrition, Exercise and Metabolism, 12, 453-60.

Miller, S., \& Bartlett, R. (1996). The relationship between basketball shooting kinematics, distance and playing position. Journal of Sports Sciences, 14, 243-253.

Montgomery D. L. (2006). Physiological profile of professional hockey players - a longitudinal comparison. Applied Physiology and Nutrition Metabolism. 31, 181-185.

Oladunni, M. O. \& Sanusi, R. A. (2013). Nutritional status and dietary pattern of male athletes in Ibadan, south western 
Nigeria. Niger. Journal of Physiological Science 28, 165 171.

Oranugo, J. B. C. (1997). Human performance factors in achieving Excellence in Sports. In C. O. Udoh, A. S. Sobi, \& J. A. Ajala, (eds) Human performance Factors in achieving Excellence in Sports. Monograph series no. 2. Ibadan: Moba Printers.

O'shea, P. (2000). Strength Quantum Fitness II (Gaining the winning Edge). Oregon: U.S.A; Patrick Books.

Penggalih, Juffire, Sudargo \& Sofro (2017). Correlation between dietary intake with anthropometry profile on youth football athlete in Indonesia. Asian Journal of Clinical Nutrition 9(1), $9-16$.

Plisk, S. (2011). Resistance Training- Part 1: Considerations in maximizing sport performance.http://www.coachesinfo.com./ Retrieved on 04/12/2011.

Pollock, M. L., Foster, C., Antholm, J., Hare, J., Farrel, P., Maksud, M., \& Andrew, A. S (1982). Body composition for Olympic skating candidates. Research Quarterly for Exercise and Sport, 150. Not complete

Position of the American Dietetic Association and the Canadian Dietetic Association. (1993). Nutrition for physical fitness and athletic performance for adults. Journal of American Dietician Association, 93, 691-696.

Pradhan, B. B., \& Behera, S. (2013). Fat free mass and fat free mass index as reference variables for expiratory and inspiratory flow rates. Iosr Journal of Pharmacy, 3(2), 2430.

Rasmussen, B., Tipton, K. D, Miller, S. L, Wolf, S. E, \& Wolfe, R. R. (2000). An oral essential amino acid, carbohydrate supplement enhances muscle protein anabolism after resistance exercise. Journal of Applied Physiology, 88, 386392.

Rosato, F. D. (1994) Fitness for wellness ( ${ }^{\text {rd }}$ ed.). Minneapolis: West Publishing. 
Salarkia, N., Kimiagar, M., \& Aminpour, A. (2004). Food intake, body composition and endurance capacity in basketball players. Medical Journal of the Islamic Republic of Iran, 18(1), 73-7.

Spaniol, F. J. (2002). Physiological predictors of bat speed and throwing velocity in adolescentbaseball players (Abstract). Journal of Strength and Conditioning Research, 16(4), 1 18.

Smith, H. K., \& Thomas, S. G. (1991). Physiological characteristics of elite female basketball players. Canadian Journal of Sports Science, 16, 289-295.

Trakman, G. L., Forsyth, A., Devlin, B. L. \& Belski, R. (2016). A Systematic Review of Athletes' and Coaches' Nutrition Knowledge and Reflections on the Quality of Current Nutrition Knowledge Measures. Nutrients 8(570), $1-23$.

Toriola A. (1999). Protocol on judo. Sport Information and Science Agency, 1-36.

Walters, W. M., Hudson, J. L., \& Bird, M. (1990). Kinematic adjustments Basketball in shooting at three distances. In: M. Nosek D, Sojka, W. E. Morrison \& P. Susanka (ed.) Biomedical Basis of Physical Education (219-233) $\left(3^{\text {rd }}\right.$ Ed.), Philadelphia: Saunders Publishers Co.

Weatherwax-Fall, D. (2012). Body composition and its effect on the sports performance spectrum. NSCA Performance Training Journal, 7(5), page number?

Williams, C., \& Rollo, I. (2015). Carbohydrate Nutrition and team sport performance. Sports Med., 45(1), 13-22.

Williams, D. P., Groing, S. B., Lohman, T. G., Harsha, D. W., Webber, L. S., \& Berson, G. S. (1992). Body Fatness and the risk of elevated blood pressure, total cholesterol and serum lipoprotein ratio in children and youth. American Journal of Public Health, 82, 358-363.

Wilmore, J. H. (1983). Body Composition in Sport and Exercise: Director for future research. Medical Sciences, Sports and Exercise, 15(1), 21-31. 